ORIGINAL ARTICLE

\title{
Declining prevalence of STI in the London sex industry, 1985 to 2002
}

\author{
H Ward, S Day, A Green, K Cooper, J Weber
}

Sex Transm Infect 2004;80:374-378. doi: 10.1136/sti.2003.009068

See end of article for authors' affiliations .....................

Correspondence to: Helen Ward, Division of Primary Care and Population Health Sciences, Imperial College London W2 1PG, UK; h.ward@imperial.ac.uk

Accepted for publication 3 March 2004

\begin{abstract}
Objectives: To describe major changes in the London sex industry between 1985 and 2002 and assess the implications for sexually transmitted infection (STI) risk.

Method: A descriptive study comparing women who first attended a sex work clinic between 1996 and 2002 and those first attending from 1985 to 1992; a nested case-control study. 1050 female sex workers took part. The setting was a specialist clinical service for sex workers based in a London genitourinary medicine (GUM) clinic, and fieldwork in west London. The main outcome measures were reported condom use and prevalent STI.

Results: Over the period of the study there was a significant increase in the proportion of sex workers not born in the United Kingdom (from 25\% to 63\%, p<0.001), and women entered sex work at an older age (median 24 years compared with 20 years, $\mathrm{p}<0.001$ ). Condom use increased (with the exception of oral sex). There was a significant decline in the proportion of participants reporting a previous STI (32\% compared with $80 \%, p<0.001)$ and the prevalence of acute STI declined from $25 \%$ to $8 \%(p<0.001)$. Acute STI was associated with younger age, younger age at first sex work, being new to sex work, and inconsistent condom use. In a multivariate analysis unprotected sex with clients was the only significant risk.

Conclusion: Major restructuring of the sex industry, including the shift to a primarily migrant workforce, has been associated with a steep decline in acute STI, undermining popular assumptions that migrant sex workers are central to the ongoing STI epidemic. We attribute the decline in acute STI to an increase in safer sex.
\end{abstract}

$\mathrm{F}$ emale sex workers in London have had a relatively low risk of sexually transmitted infections (STI), including HIV, and a high level of condom use. ${ }^{1-3}$ Peer norms and networks, together with specialist health services, have contributed to health and safety in the industry in the United Kingdom and many parts of Europe. ${ }^{4-8}$

However, by the second half of the 1990s, specialist health services in Europe were reporting increasing numbers of nonEuropean prostitutes in the local workforce (see www. europap.net). This demographic change, reflecting global population movements, posed a challenge to health promotion campaigns: how to sustain the high levels of safer sex characteristic of professional prostitution? It has been unclear whether this migration, often from regions of the world with higher risks of STI and HIV, would increase risks among sex workers in Europe. A few studies have found higher risks of HIV and STI in migrant sex workers, but others have not. ${ }^{9-12}$

In the United Kingdom there has also been an increase in the rate of bacterial STI in the UK population generally, including outbreaks of syphilis, and a crisis in access to sexual health services in the United Kingdom. ${ }^{13}{ }^{14}$ We hypothesised that changes within the sex industry would weaken established norms of occupational health and safety. Given the concurrent STI epidemic in the United Kingdom, we were concerned that sex workers would be at greater risk of infection. We therefore established a study to describe changes in the sex industry workforce and to analyse the impact of these changes on sexual health.

\section{METHODS}

From 1985 to 2002, female sex workers attending the Department of Genitourinary Medicine at St Mary's Hospital were invited to attend a specialist service, the Praed Street Project Clinic, for screening and health care. In addition to referrals from the walk-in sexual health clinic, we received referrals through linked outreach services to local streets and sex work venues, and a drop-in centre run by the Praed Street Project. ${ }^{2}$ From 1985 to 1992 and again from 1996 to 2002, baseline data were collected on 1050 women at their first clinic visit using a standardised proforma. The data were linked to results of diagnostic and screening tests. Women were screened for one or more of gonorrhoea, chlamydia, trichomonas, syphilis, HIV, and hepatitis B. Screening was based on routine diagnostic methods (see Ward et $a l^{3}$ ). Gonorrhoea was detected using Gram stain with culture confirmation. Direct immunofluorescence was used to detect chlamydia from cervical specimens until 1993; subsequently an enzyme immunoassay (EIA) test was used until 1998 when a nucleic acid amplification test was introduced; trichomoniasis was diagnosed through direct microscopy of a wet mount from vaginal secretions. A diagnosis of new genital herpes was based on positive culture from a clinical lesion in someone with no previous history. Serum samples were tested for antibodies to HIV-1 and HIV-2 using routine ELISA screening tests with confirmation; hepatitis B core antibody was used as evidence of past infection; syphilis was diagnosed using TPHA, VDRL, and fluorescent treponemal antibody (FTA) tests. Newly diagnosed syphilis was distinguished by clinical history and serological profile.

Baseline data on the first 402 women included in this article have previously been published in a separate analysis. ${ }^{3}$ Baseline data were not collected in a standard way from 1993 to 1995 and therefore these years have not been included in most analyses, with the exception of country of birth which

Abbreviations: EIA, enzyme immunoassay; FTA, fluorescent treponemal antibody; GUM, genitourinary medicine; STI, sexually transmitted infections 
was asked of all patients registering with the service throughout, and is therefore included for completeness in the description of trends (see fig 1).

Members of the research team carried out fieldwork during two phases, 1988-91 and 1998-2002, visiting areas of street prostitution, magistrates' courts, sex work businesses (flats and agencies), prisons, and drugs projects.

From 1989 to 1991 we made 184 fieldwork visits to three street areas and three magistrates' courts, meeting 274 different women. In 1999-2001, field work included twice weekly attendance at the Praed Street Project drop-in clinic for 12 months, six visits to another local drop-in, visits to 12 saunas, visits to 48 flats in two parts of London, one agency, two street areas, and one magistrates' court. In both periods we collected phone numbers from adverts in local phone boxes and newspapers. Fieldwork involved one or more members of the team visiting the areas and talking to people associated with the sex industry. Most of this fieldwork was conducted alongside outreach services, including health promotion relating to safer sex and drug use. Notes were kept from observations and informal interviews. Where possible data were collated on the numbers of sex workers/ sex businesses and their characteristics. We also enumerated the working population locally. In this paper, we use these fieldwork data to assess potential biases associated with the clinic sample.

Data were analysed by reading through notes made at the time, transcripts of interviews, and collating information on numbers and some demographic data about contacts made.
In the clinic and during fieldwork, we communicated primarily in English, but could also converse in Spanish, Portuguese, and French. Translators were sometimes available for other languages but, more commonly, non-English speakers communicated through friends and colleagues.

Early year of recruitment to the study was the strongest determinant of STI and so, to look at other factors associated with STI, we carried out a nested case-control study matching for year of recruitment. Cases were defined by having one or more STI (gonorrhoea, chlamydia, trichomoniasis, infectious or early latent syphilis, first episode genital herpes, or first episode genital warts) at recruitment. Two controls were randomly selected for each case from those sex workers who had registered in the same year and screened negative. The sample size of the case-control study was based on the total number of cases eligible.

\section{Data management and analysis}

Data from all studies were stored without individual identifying information. Numeric data were entered into a spreadsheet, checked, and exported to SPSS for analysis. Fieldwork notes were entered into a word processing package and then exported into a qualitative analysis program for analysis. We created four broad categories for country of birth in order to analyse demographic changes: United Kingdom, developed, developing, and transitional economies (former Soviet states and east/central Europe). Condom use was analysed using two categories: always or not always. We compared those recruited in the earlier period, from 1985 to 1992, with those recruited later from 1996 to 2002. Simple

\begin{tabular}{|c|c|c|c|}
\hline & $\begin{array}{l}1985-92 \\
(n=498)\end{array}$ & $\begin{array}{l}1996-2002 \\
(n=552)\end{array}$ & $p$ Value \\
\hline \multicolumn{4}{|l|}{ Age } \\
\hline Range & $16-59$ & $16-46$ & \\
\hline Median (IQR) & $25(21,29)$ & $26(23,31)$ & $<0.001$ \\
\hline Missing & 2 & 3 & \\
\hline \multicolumn{4}{|l|}{ Country of birth } \\
\hline UK & $346(74.9 \%)$ & $203(36.9 \%)$ & $<0.001$ \\
\hline Developed & $90(19.5 \%)$ & $89(16.2 \%)$ & \\
\hline developing & $22(4.8 \%)$ & $149(27.1 \%)$ & $<0.001$ \\
\hline Transitional & $4(0.9 \%)$ & $109(19.8 \%)$ & $<0.001$ \\
\hline Missing & 36 & 2 & \\
\hline \multicolumn{4}{|c|}{ Months of sex work } \\
\hline Range & $1-324$ & $1-216$ & \\
\hline Median (IQR) & $24(10,60)$ & $12(4,36)$ & 0.004 \\
\hline Missing & 127 & 128 & \\
\hline \multicolumn{4}{|c|}{ Age at start of sex work } \\
\hline 16 or under & 42 (11.3\%) & $21(5.0 \%)$ & 0.01 \\
\hline $17-19$ & $108(29.1 \%)$ & $51(12.1 \%)$ & $<0.001$ \\
\hline $20-29$ & 189 (50.9\%) & $268(63.8 \%)$ & $<0.001$ \\
\hline 30 or older & $32(8.6 \%)$ & $80(19.0 \%)$ & $<0.001$ \\
\hline Range & $11-50$ & $12-52$ & \\
\hline Median (IQR) & $20(18,24)$ & $24(21,28)$ & \\
\hline Missing & 127 & 132 & \\
\hline \multicolumn{4}{|l|}{ Sex work sector } \\
\hline Club/sauna & $52(12.5 \%)$ & 71 (14.3\%) & NS \\
\hline Escort/madam & $161(38.8 \%)$ & $190(38.4 \%)$ & NS \\
\hline Private & $46(11.1 \%)$ & $16(3.2)$ & $<0.001$ \\
\hline Flat & 81 (19.5\%) & $170(34.3 \%)$ & $<0.001$ \\
\hline Street & 74 (17.8\%) & $16(3.2 \%)$ & $<0.001$ \\
\hline Other & $1(0.2 \%)$ & $32(6.5 \%)$ & $<0.001$ \\
\hline \multirow{2}{*}{\multicolumn{4}{|c|}{ Past STI }} \\
\hline & & & \\
\hline Gonorrhoea & $177 / 352(50.3 \%)$ & $36 / 494(7.3 \%)$ & $<0.001$ \\
\hline Chlamydia & $111 / 352(31.5 \%)$ & $71 / 494(14.4 \%)$ & $<0.001$ \\
\hline Genital herpes & 49/352 (13.9\%) & $30 / 494(6.1 \%)$ & $<0.001$ \\
\hline Syphilis & $9 / 352(2.6 \%)$ & $13(2.6 \%)$ & NS \\
\hline Anyt & $281 / 352(79.8 \%)$ & $159 / 494(32.2 \%)$ & $<0.001$ \\
\hline
\end{tabular}




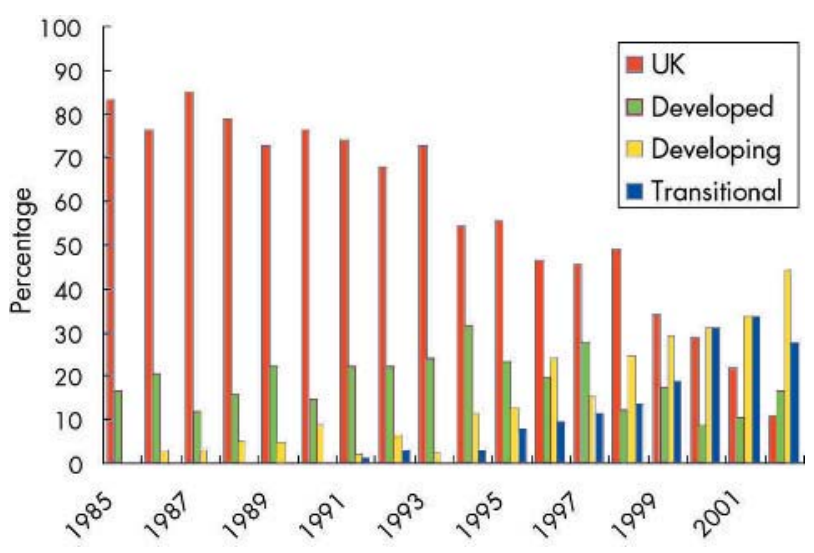

Figure 1 Type of country of birth of sex workers by year of first attending the Praed Street Project Clinic, 1985-2002*. (*In this figure data have been included for all years from 1985 to 2002 using routine clinic registration data for the years 1993 to 1995 . See methods for description of the country categories.)

univariate analysis was carried out for most comparisons using $\chi^{2}$ tests for categorical variables, and Mann-Whitney $U$ test to compare continuous variables. In the case-control study we carried out univariate logistic regression to produce odds ratios and 95\% confidence intervals. Multivariate analysis was carried out using forward conditional logistic regression, testing in the model the effect of those variables significantly associated on univariate analysis, or those variables of borderline significance that are known determinants of risk. Fieldwork notes and transcripts were analysed by content; workplaces and the local working population were mapped.

\section{Consent and ethics}

Approval was obtained from the local research ethics committee. In the clinic, baseline data were requested as part of the registration visit, and specific consent was obtained for interviews. Screening was conducted with appropriate counselling and consent; infections were managed according to standard clinic protocol. During fieldwork, consent was obtained for interviews and for access to workplaces and projects.

\section{RESULTS}

\section{Clinic sample}

In all, 1050 registered with the clinic during the two study periods, 1985-1992 and 1996-2002 (see table 1). Later recruits were older, less likely to have been born in the United Kingdom, and attended earlier in their sex work careers; $40 \%$ attended within the first 6 months. The age at which women had entered prostitution increased significantly; fewer women reported first work before the age of 20 (17\% compared with $40 \%$ in the earlier group), and more started in their 30 s or older (19\% compared with $9 \%$ in the earlier group). More women worked in flats or "other" ways, referring primarily to direct advertising on the internet and the adult entertainment industry. At first visit the proportion of women reporting past STI declined substantially, from $80 \%$ to $32 \%$.

Figure 1 shows the change in geographical origin of sex workers in more detail, including figures for the intervening years, which were available from routine data. The proportion of workers of UK origin fell in the mid-1990s; the biggest increase was in sex workers from the transitional economies of eastern Europe and the former Soviet Union, and from developing countries in Asia, South America, and Africa.

Condom use for vaginal sex with clients increased to $98 \%$ by 1990 , and has stayed at that level. In contrast, condom use for oral sex with clients has declined; consistent use was reported by $41 \%$ of women in 1985-6, rising to $91 \%$ by 1990 ; it has subsequently declined with only $66 \%$ of women reporting universal use in $2002\left(\chi^{2}=21.94, p \leqslant 0.001\right)$. The proportion of women using condoms for anal sex with clients rose to $94 \%$, and more women reported selling this type of sex, increasing from five in the earlier period ( $1 \%$ of total) to 34 in the later period ( $6 \%$ of total). Systematic condom use with non-commercial partners increased from $8 \%$ of women in $1985-6$ up to $44 \%$ in 2003.

Table 2 shows the results of screening carried out at first visit. The prevalence of acute STI, including gonorrhoea and chlamydia, decreased significantly from the earlier to the later group. Newly diagnosed syphilis increased but not significantly along with HIV, past hepatitis B, and previous syphilis. HIV and hepatitis B were most strongly associated with injecting drug use in the earlier group ${ }^{3}$ and with origin from high prevalence areas in the later group.

\section{Analysis of vulnerability to infection}

In the nested case-control study, we included 128 cases of acute STI and 256 controls. Cases included 59 Chlamydia trachomatis, 34 newly diagnosed genital warts, 23 trichomoniasis, 22 gonorrhoea, nine first clinical episode genital herpes, and two early latent syphilis. Most women (112) had a single infection, but 12 had two infections and four had three. Table 3 shows factors associated with an acute STI. Univariate analysis suggested that younger age now, younger age at first sex work, and being new to sex work were all associated with increased risk. Having a boyfriend increased the risk, and using condoms with him, and using condoms with all clients for vaginal sex reduced the risk. Drug use, working outside London or the United Kingdom, being nonUK born, and workplace were not associated with increased risk. The results of a multivariate analysis are also shown in

Table 2 Baseline prevalence of infections comparing sex workers registering with clinic 1985-92 with those in 1996-2002*

\begin{tabular}{|c|c|c|c|c|c|}
\hline & \multicolumn{2}{|l|}{$1985-92$} & \multicolumn{2}{|l|}{ 1996-2002 } & \multirow[b]{2}{*}{ Change } \\
\hline & Prevalence & $\%$ & Prevalence & $\%$ & \\
\hline Any acute STI† & $99 / 398$ & 24.9 & $29 / 367$ & 7.9 & $-68 \%(p<0.001)$ \\
\hline Gonorrhoea & $18 / 396$ & 4.5 & $4 / 364$ & 1.1 & $-75 \%(p<0.01)$ \\
\hline Chlamydia & $42 / 393$ & 10.7 & $17 / 354$ & 4.8 & $-55 \%(p<0.01)$ \\
\hline HIV & $4 / 357$ & 1.1 & $3 / 200$ & 1.5 & $+36 \%$ (NS) \\
\hline Hepatitis B‡ & $27 / 417$ & 6.5 & $28 / 307$ & 9.1 & $+40 \%$ (NS) \\
\hline Syphilis previous treatment & $9 / 367$ & 2.5 & $13 / 279$ & 4.7 & $+88 \%$ (NS) \\
\hline Syphilis newly diagnosed & $3 / 367$ & 0.8 & $6 / 279$ & 2.2 & $+175 \%$ (NS) \\
\hline
\end{tabular}

*The denominators vary in this table since not all sex workers consented to screening for all STIs.

†One or more of gonorrhoea, chlamydia, trichomoniasis, first episode genital herpes, first episode genital warts, infectious syphilis.

tHepatitis B anti-core positive, indicating previous infection. 
Table 3 Case-control study: crude and adjusted odds ratios for risk of having an infection (one or more of gonorrhoea, chlamydia, trichomoniasis, first episode genital herpes, first episode genital warts, infectious syphilis) at first visit

\begin{tabular}{|c|c|c|c|c|}
\hline & Univariate & & Multivariate & \\
\hline & Odds ratio $(95 \% \mathrm{Cl})$ & $\mathrm{p}$ Value & Odds ratio $(95 \% \mathrm{Cl})$ & $\mathrm{p}$ Value \\
\hline $\begin{array}{l}\text { Age (years) } \\
\text { Age first sex work (years) } \\
\text { Time in sex work (years) } \\
\text { Any unprotected vaginal sex with boyfriend } \\
\text { Any unprotected vaginal sex with clients }\end{array}$ & $\begin{array}{l}0.91(0.87 \text { to } 0.95) \\
0.92(0.87 \text { to } 0.97) \\
0.94(0.88 \text { to } 1.00) \\
2.28(0.94 \text { to } 5.53) \\
2.10(0.97 \text { to } 4.54)\end{array}$ & $\begin{array}{l}<0.001 \\
0.001 \\
0.06 \\
0.07 \\
0.06\end{array}$ & $\begin{array}{l}0.95(0.82 \text { to } 1.11) \\
0.95(0.81 \text { to } 1.10) \\
0.95(0.78 \text { to } 1.14) \\
1.54(0.60 \text { to } 3.97) \\
4.42(1.51 \text { to } 12.95)\end{array}$ & $\begin{array}{l}\text { NS } \\
\text { NS } \\
\text { NS } \\
\text { NS } \\
0.007\end{array}$ \\
\hline
\end{tabular}

table 3, with a model that included factors significantly associated with STI and those of borderline significance. The best model showed infections to be associated with inconsistent condom use with clients.

\section{Assessment of potential bias in clinic sample}

Many variables are incomplete. To check for biases, we compared those with missing information on one key variable-time in sex work-with those who had more complete data. No significant differences were found in country of birth, age, history of drug use, or workplace (data not shown).

Clinic studies of this kind are also subject to selection bias. We used fieldwork data to test whether the major changes described above were mirrored in the local sex work population.

In our early fieldwork the majority of women were British. Visits to flats, saunas, and escort agencies in the second period of fieldwork confirmed the demographic shift in the workforce. At the end of the 1990s, we found that 92/143 $(64 \%)$ of flat and sauna workers in one area of central London were from transitional economies; the majority lacked legal rights in the United Kingdom. We also met women from other parts of the world including Thailand, South America, and Africa. Sex work businesses had developed extensive international links-for example, one London agency had 354 sex workers on its books in 1999 who came from all over the world and who were working for this agency from 16 different countries.

Fieldwork also confirmed the shift from street to indoor work. In the second half of the 1980s there was a visible and varied street prostitution sector in west London that had existed for many decades. In fieldwork from 1998-2000, we met far fewer street workers; those we met were largely from the United Kingdom and often had multiple health and social problems associated with drug use. Evidence of the growth in indoor work was also provided by the fivefold increase in phone numbers advertised in local newspapers and, before a legal change in 2000, telephone boxes.

In fieldwork, we met women who did not use sexual health services. Some migrants were concerned that clinics would inform the immigration authorities, who would then deport them; others lacked knowledge, language proficiency and the confidence or freedom to consult services independently. Some UK drug users did not access sexual health care but were in contact with drug service outreach.

\section{DISCUSSION}

We have documented a two thirds decline in acute STI among sex workers in London. This finding is particularly striking in the context of a doubling of gonorrhoea and chlamydia infections since the mid-1990s in the United Kingdom. Sex workers are protecting themselves and their partners effectively from these infections during a period of rapid restructuring of the industry involving major changes in the workforce. By the end of the 1990s, sex workers were less likely to be from the United Kingdom, more likely to work indoors, to have been older when they entered sex work, and to have attended our project earlier in their careers.

The study is limited by the many missing values for some variables, an inevitable result of integrating research with the ongoing service delivery to a vulnerable population. Changes to testing practices may mean that we have missed a number of infections-for example, less that half the women in the later group were screened for HIV and syphilis at their first visit. This should not have biased the associations found in the case-control study, but may have altered the precision of our prevalence estimates and the temporal trends if, for example, women at higher risk were less likely to be screened in the later group. Changes in diagnostic methods over time may also have affected our comparisons; tests for chlamydia have become more sensitive and therefore we may be underestimating the initial prevalence and the decline may be even greater.

We attribute the decline in acute STI to an increase in safer sex. Despite a significant reduction in condom use for oral sex, condoms are used almost universally with clients for vaginal sex and increasingly with non-commercial partners. We attribute the small rise in serological markers of current and past infection with HIV, hepatitis B, and past syphilis to migration from higher prevalence areas; most cases were not infectious.

Individual risk of acute STI was largely defined by year. In addition, younger age and inconsistent condom use with clients increased risk; there was no association with country of origin. The association of STI with younger age is not confined to sex workers, but young entry into sex work also provides a measure of general social and economic disadvantage.

Our results suggest that outreach projects should emphasise condom promotion for oral sex, strengthen appropriate language and cultural skills, and focus on the youngest workers who will be most at risk as well as those who are not in contact with clinical services. Clinical services too should respond to the changes we have observed by increasing pharyngeal screening for infections, and by ensuring sex workers and their partners are screened for syphilis and vaccinated against hepatitis $B$.

In conclusion, we have demonstrated that within the sex industry, in contrast with many other sections of the population, safer sex practices can be sustained over time despite, or perhaps to some extent because of, a rapidly changing workforce. This is in part explained by the existence of a network of health projects and some industry managers who support health and safety initiatives. It must also be attributed to the change in the workforce. Many of the women who migrate and work in the sex industry today are well educated and motivated to improve their life chances. They rarely use drugs (data not shown) and consider prostitution a transitory way of acquiring education and language skills. In this context, health and safety messages are easy to get across. Clearly, these findings are not true for 
all sex workers: a small number of migrants are "trafficked" against their will, and a proportion of the young women we met from the United Kingdom were highly vulnerable, often through drug addiction and/or abuse. But for the majority, it is general education and motivation for self improvement that enables safer sex messages to be effectively consumed. Interventions to improve women's general education and increase their personal motivation are essential if more targeted interventions are to be effective.

\section{ACKNOWLEDGEMENTS}

This study was supported by the Wellcome Trust (grant number 053592). Earlier research was funded by the Medical Research Council, AVERT, North West Thames Regional Health Authority, and the Jefferiss Research Trust.

Thanks to all participants, and to the many collaborators who have contributed to this work over the years including Pippa Greer, Anna Pallecaros, and other staff of the Praed Street Project and the Jefferiss Wing Clinic.

\section{Authors' affiliations}

H Ward, A Green, K Cooper, Division of Primary Care and Population Health Sciences, Imperial College London, London W2 IPG, UK

S Day, Department of Anthropology, Goldsmith's College, London SE14 6NW, UK

J Weber, Division of Medicine, Imperial College London, London W2 IPG, UK

\section{REFERENCES}

1 Day S, Ward H, Harris JRW. Prostitute women and public health. BMJ 1988:297:1585.

2 Ward H, Day S, Mezzone J, et al. Prostitution and risk of HIV: female prostitutes in London. BMJ 1993;307:356-8.

3 Ward H, Day S, Weber JN. Risky business: health and safety in the sex industry over a 9 year period. Sex Transm Infect 1999;75:340-3.

4 Ballesteros J, Clavo P, Castilla J, et al. Low seroincidence and decrease in seroprevalence of HIV among female prostitutes in Madrid. AIDS 1999;13:1 143.

5 Day S, Ward H. Sex workers and the control of sexually transmitted disease. Genitourin Med 1997;73:161-8.

6 Mak R, ed. EUROPAP: European intervention projects AIDS prevention for prostitutes. Gent: Academia Press, 1996

7 Vioque J, Hernandez-Aguado I, Garcia E, et al. Prospective cohort study of female sex workers and the risk of HIV infection in Alicante, Spain (1986-96) Sex Transm Infect 1998;74:284-8.

8 Spina M, Mancuso S, Sinicco A, et al. Human immunodeficiency virus seroprevalence and condom use among female sex workers in ltaly. Sex Transm Dis 1998;25:451-4

9 D'Antuono A, Andalo F, Carla, et al. Prevalence of STDs and HIV infection among immigrant sex workers attending an STD centre in Bologna, Italy. Sex Transm Infect 2001;77:220.

10 The EPI-VIH Study Group. HIV infection among people of foreign origin voluntarily tested in Spain. A comparison with national subjects. Sex Transm Infect 2002;78:250-254.

11 Hiltunen-Back E, Haikala $O$, Koskela $\mathrm{P}$, et al. Epidemics due to imported syphilis in Finland. Sex Transm Dis 2002;29:746-51.

12 Matteelli A, Beltrame A, Carvalho A, et al. Chlamydia trachomatis genital infection in migrant female sex workers in ltaly. Int J STD AIDS 2003;14:591-5.

13 Health Protection Agency. Renewing the focus: HIV and other sexually transmitted infections in the United Kingdom in 2002. An update November 2003. London: Health Protection Agency, 2003.

14 Kinghorn G. Patient access to GUM clinics. Sex Transm Infect 2001;77:1-3.

\section{Making Health Care Safer 2004}

21-22 October 2004

Royal College of Physicians, London

A two day conference for all professionals dedicated to providing safer health care for all. Register now! Early booking discount available.

See website for details: www.quality.bmipg.com 